See discussions, stats, and author profiles for this publication at: https://www.researchgate.net/publication/329708270

\title{
Perceptions of Well-Being, Resilience and Stress Amongst a Sample of Merchant Seafarers and Superintendents
}

Article · December 2018

DOI: 10.1007/540152-018-0129-1

\section{CITATIONS}

4 authors, including:

58. Joanne McVeigh

National University of Ireland, Maynooth

36 PUBLICATIONS 293 CITATIONS

SEE PROFILE

Q William Kavanagh

Cork Institute of Technology

11 PUBlications 31 CITATIONS

SEE PROFILE

Some of the authors of this publication are also working on these related projects:

Doctoral Training for Development in Africa View project

Project Research methods classes View project
369

Malcolm Maclachlan

National University of Ireland, Maynooth

277 PUBLICATIONS 4,898 CITATIONS

SEE PROFILE 


\title{
Perceptions of Well-Being, Resilience and Stress Amongst a Sample of Merchant Seafarers and Superintendents
}

\author{
Joanne McVeigh $^{1,2} \cdot$ Malcolm MacLachlan $^{1,2,3,4} \cdot$ Camille Coyle $^{5} \cdot$ Bill Kavanagh $^{6}$
}

Received: 28 June 2018 / Accepted: 21 November 2018

(C) Springer-Verlag GmbH Germany, part of Springer Nature 2018

\begin{abstract}
Significant changes in the seafaring industry have increased occupational demands at sea, challenging the psychosocial wellbeing of seafarers. The primary aim of this study was to explore perceptions and experiences of well-being, resilience and stress amongst a sample of merchant seafarers and superintendents. Exploring perceptions of well-being, resilience and stress amongst this sample is required to inform organisational policies in the interest of improving working and living conditions for maritime workers. Semi-structured interviews $(n=11)$ and one focus group $(n=13)$ were conducted with superintendents, officers and ratings/crew of a large shipping company to explore their perceptions of well-being, resilience and stress. Analysis was conducted using descriptive and interpretive qualitative methods. Findings were interwoven by two critical themes. The first, recent changes, was expressed by participants in relation to fewer opportunities to relieve stress in recent years due to reduced socialisation and shore leave. The second, organisational justice, was indicated by participants regarding the importance of a just work environment. Although depression and other forms of psychosocial distress may be experienced individually, their causes are multifaceted and cannot be addressed only at the level of individual functioning. We must address causes of perceived injustice at the organisational and industry levels, alongside supporting the capacity of individuals to cope with challenging situations. A working environment that is experienced as supportive and just is therefore crucial for individually focused psychosocial interventions to be optimally applied.
\end{abstract}

Keywords Merchant seafarers $\cdot$ Maritime $\cdot$ Psychosocial $\cdot$ Well-being $\cdot$ Resilience $\cdot$ Stress $\cdot$ Organisational justice $\cdot$ Shell

\section{Introduction}

\section{Psychosocial Health of Seafarers}

For the approximately $1,647,500$ merchant seafarers globally (BIMCO and International Chamber of Shipping 2015), working and living conditions on-board have been significantly altered due to faster turnaround schedules in ports, increased use of technology, decreased manning, labour intensification, and social isolation (Allen et al. 2007; Borovnik 2011; Dimitrova and Blanpain 2010; Project MARTHA 2016). As emphasised by the ITF Seafarers' Trust (2017), fast technological advancement, increased automation, decreased personnel, more diverse crew, lack of shore leave, faster turnaround schedules, and a hierarchical command system may all lead to social isolation on-board.

Seafarers are an occupational cohort amongst those at the highest risk for stress (Lipowski et al. 2014), which may

Electronic supplementary material The online version of this article (https://doi.org/10.1007/s40152-018-0129-1) contains supplementary material, which is available to authorized users.

Joanne McVeigh

Joanne.McVeigh@mu.ie

1 Department of Psychology, Maynooth University, Maynooth, Co. Kildare, Ireland

2 Assisting Living \& Learning (ALL) Institute, Maynooth University, Maynooth, Co. Kildare, Ireland

\footnotetext{
Centre for Rehabilitation Studies, Stellenbosch University, Cape Town, South Africa

4 Olomouc University Social Health Institute (OUSHI), Palacký University, Olomouc, Czech Republic

5 Health Research Board, Dublin, Ireland

6 National Maritime College of Ireland, Co. Cork, Ireland
} 
adversely influence their mental health (Jeżewska et al. 2006). In the maritime industry, psychological issues such as depression, anxiety, suicide, and alcohol or drug dependence, are recognised health problems (MacLachlan et al. 2013). On non-passenger ships, minor mental health problems are the most common type of ill-health (Carter 2011). Stressors including months or years away from home; loneliness; bullying; fatigue; lack of shore leave; and short turnaround schedules in ports, may cause anxiety and depression, and for some seafarers, suicide (Iversen 2012).

An estimated $1.4 \%$ of all deaths globally were as a result of suicide in 2015 (WHO n.d.). Suicide in the seafaring population may be considerably more common (Slišković 2017). The U.K. Protection and Indemnity Club (Velankar 2017) reported that $4.4 \%$ of all deaths on-board were attributable to suicide from 2014 to 2015 , which proliferated to $15.3 \%$ for the year 2015-2016. In a review of seafarers' depression and suicide, Mellbye and Carter (2017) reported that investigations of depression and suicide amongst seafarers indicate improvement, although a number of recent case series suggest that suicide remains problematic.

Although depression and other forms of psychosocial distress may be experienced individually, their causes are multifaceted and cannot be addressed only at the level of individual functioning. For example, quality of social relationships is related to depression (Teo et al. 2013); suggesting that the social isolation experienced by seafarers on-board (Alderton et al. 2004; ITF Seafarers' Trust 2017; Mission to Seafarers 2018) may affect their mental health. Organisational justice is also associated with mental health (Ndjaboué et al. 2012). This suggests that the experience of inequities by seafarers from lowand middle-income countries (LMICs), such as linking nationality to senior positions, longer tours of duty, and dissimilar pay rates for the same work (Baylon and Santos 2015; Borovnik 2011; Carter 2005; Dimitrova and Blanpain 2010; MacLachlan 2017a) may also affect their mental health. As Carter (2005, p. 62) suggests, for seafarers "perceived inequity can contribute to distress". Indeed, the social gradient may be a substantial stress factor on-board (Oldenburg et al. 2009).

\section{Organisational Justice}

Organisational justice refers to individuals' perceptions of fairness in relation to an organisation's policies, pay systems and practices (Furnham 2012). Organisational justice theory addresses the fairness of several work-related aspects (Aamodt 2013). These aspects include interactional justice, relating to interpersonal aspects, such as bullying in the workplace; procedural justice, signifying a perception that the procedures underpinning a pay decision are fair; and distributive justice relating to pay diversity, or more specifically, rewards that are distributed and to which individuals, as a percentage of the overall resources of the group (Carr 2005). As suggested by MacLachlan (2016, p. 1), "maintaining privilege, breaking the psychological contract, and bullying all flourish in an environment devoid of fairness, or even the expectation of it". While the concept and perceptions of fairness in organisations differ across cultures and individuals (Furnham 2012), job satisfaction is likely to decrease when employees perceive organisational injustice (Schultz and Schultz 2016). For example, McAuliffe et al. (2009) reported that perceptions of organisational justice strongly correlated with level of job satisfaction amongst mid-level health workers in Malawi. Indeed, organisational justice significantly influences job satisfaction and dissatisfaction, as well as intent to leave and broader well-being (Furnham 2012).

Organisational injustice, particularly for seafarers from LMICs, is evident in the maritime sector. The maritime industry has undergone significant transformation in recent years, including labour intensification and social isolation (Allen et al. 2007; Borovnik 2011; Dimitrova and Blanpain 2010; Project MARTHA 2016), alongside a lack of shore leave (Clare 2015; Kahveci 2007; Kantharia 2017; Oldenburg and Jensen 2012; Shoretoo 2015; Walters and Bailey 2013). For example, with a sample of 6461 seafarers across 11 countries, Jensen et al. (2006) reported that the majority of seafarers worked each day of the week, and an average of 67 to 70 hours weekly throughout durations of 2.5 to 8.5 months on-board; moreover, seafarers from South-East Asian countries were on-board for longer durations, and had fewer officers and older seafarers than seafarers from higher income countries. Indeed, seafarers of lower ranks from LMICs typically endure the poorest terms and conditions of employment, with the expression of "sweat ships" denoting similar exploitation of employees (MacLachlan 2017a). Accordingly, urgent human rights issues (Human Rights at Sea 2016) and organisational justice concerns in the maritime sector, particularly so for seafarers from LMICs, signify the need for reevaluation of working terms and conditions for seafarers by maritime organisations and the industry.

\section{Well-Being}

According to the OECD (Organisation for Economic Cooperation and Development) (2017, p. 23), various factors are associated with well-being, including "income, jobs, housing, health status, skills, the environment, governance and personal safety. The importance of more experiential elements of life, such as social connections, work-life balance and subjective well-being, is also increasingly recognised across these approaches". Although definitions are highly debated, wellbeing therefore alludes to a combination of psychological, emotional, physical, social and economic health (UNCTAD 2016).

Importantly, factors that influence the well-being and performance of maritime personnel are imbedded at several levels of work, including at the levels of the task, individual, team, organisation and industry (MacLachlan et al. 2013). Effectively addressing the well-being of maritime workers therefore requires 
addressing well-being at the different system levels. We must also therefore reconsider incentives at the organisational and industry levels that may best support seafarers' well-being.

\section{Resilience}

Resilience refers to "the positive psychological capacity to rebound, to 'bounce back' from adversity, uncertainty, conflict, failure or even positive change, progress and increased responsibility" (Luthans 2002, p. 702). While resilience has traditionally been proposed as being dispositional and trait-like, there is evidence that it may be state-like and capable of development (Luthans et al. 2006; Maddi and Khoshaba 2005). Resilience therefore comprises thoughts, behaviours and actions that may be learnt and strengthened (American Psychological Association n.d.). Research indicates that resilience can protect individuals against adverse impacts of stress (Friborg et al. 2006; Hjemdal et al. 2006; Ong et al. 2006; Pietrzak et al. 2010). For example, with a sample of 387 merchant seafarers, Doyle et al. (2016) reported that self-reported higher levels of resilience was significantly associated with lower levels of perceived stress.

It is proposed that training programmes that strengthen resilience can increase health, well-being and quality of life (Leppin et al. 2014). Psychological resilience training in the shipping sector could support safety and strengthen the well-being of employees (March on Stress 2013). As suggested by Carter (2005), research needs to focus on the organisation of work, in addition to the resilience, coping strategies and motivations of seafarers, with interventions aiming to modify these factors.

One trajectory to resilience is personality hardiness, which Bartone (2006, p. 131) describes as "a characteristic sense that life is meaningful, we choose our own futures, and change is interesting and valuable". The resilience construct of hardiness has been empirically proven to be a protective resource against adverse effects of stress (Bartone 1999; Bartone and Hystad 2010). Hardiness is conceptualised as incorporating three components: (1) challenge, signifying the belief that stressful changes are an opportunity to grow in knowledge and ability; (2) commitment, the view that no matter what difficulties are presented, it is important to stay involved with what is occurring instead of detaching and alienating oneself; and (3) control, the belief in turning stress from potential disasters into opportunities for growth (Maddi 2013). In relation to the maritime sector, with a sample of 413 Filipino merchant seafarers, Hystad and Bye (2013) reported that personal values and personality hardiness explained a significant amount of variance in relation to self-reported safety behaviour at sea. The researchers recommended a focus on hardiness and personal values regarding the selection and training of maritime workers, and when planning interventions to support safety in maritime companies (Hystad and Bye 2013).

Notably, in relation to the explanatory power of organisational justice, well-being and resilience, organisational justice is an organisational or industry level variable, while well-being and resilience are individual or group level variables. The explanatory power of each of these variables is therefore more in focus at different system levels. These variables may also interact and contribute to more explanatory power for each variable. For example, a lack of organisational justice at the organisational or industry levels may conceivably influence individuals' well-being, which may contribute to more explanatory power for both variables.

\section{The Shell Health Pilot Resilience Programme}

This research was conducted in association with Shell, ${ }^{1}$ a company recognised for its ardent approach to many of the challenges facing seafarers, as the recipient of the inaugural Global Healthy Workplace Award 2013 (Global Centre for Healthy Workplaces 2013). One psychosocial programme that has been implemented by the company is the Shell Health resilience programme, a resilience-training programme aiming to support the thriving of employees both on- and off-shore (Jacobs 2013; McVeigh et al. 2017). The resilience programme modules were developed by Shell Health professionals, based on the American Psychological Association's theory of resilience (R. Stilz, personal communication, November 1, 2018). Resilience is part of the company's holistic health programme, which includes numerous programmes - "think well" (positive psychology), "move more" (exercise), "eat well" (nutrition), "breathe well" (smoking cessation), and "sleep well" (sleep) (T. Lillington, personal communication, November 2, 2018).

The resilience programme is a voluntary programme, incorporating elements of positive psychology, cognitive behavioural therapy, neuro-linguistic programming, and leadership training. Launched onshore in 2009, the programme was subsequently adapted and launched as a pilot resilience programme at sea between April and December 2014, with an intervention group of 21 vessels or approximately half of the company's fleet. Notably, the resilience programme modules themselves were not adapted for the pilot programme at sea, but rather the delivery was adapted to take into account staggered crew and changes of facilitators.

Officers, who acted as lay facilitators of the modules, administered the programme to teams on-board. A small number of officers were trained as facilitators throughout a 1-hour session at an annual officers' conference onshore. During this session, participants were given the opportunity to share their own views of resilience; then a brief conceptual background was given, followed by a summary of the experience of the company with the programme; the subsequent main focus was providing guidance for facilitators (R. Stilz, personal communication,

\footnotetext{
${ }^{1}$ The term Shell in this article refers to Shell International Trading and Shipping Company Limited (STASCo).
} 
November 1, 2018). Using a peer-to-peer training scheme, officers trained other officers on-board so that the programme could continue when a trained facilitator disembarked or transferred between ships. Although facilitators guided the activities and discussions, the modules were highly interactive and drew considerably on the experiences of participants. Notably, the full programme materials were sent to vessels.

The resilience programme consists of 12 modules, which are approximately 40-60 minutes in duration. Each of the 12 modules focuses on a specific aspect related to resilience: (1) Introduction-What is resilience?; (2) Maintain a hopeful outlook; (3) Take care of yourself; (4) Make connections; (5) Avoid seeing crises as insurmountable problems; (6) Nurture a positive view of yourself; (7) Look for opportunities for selfdiscovery; (8) Accept that change is a part of living; (9) Keep things in perspective; (10) Move toward your goals; (11) Take decisive actions; and (12) Being grateful can accomplish more.

\section{Research Aim}

There is a call for more research assessing seafarers' psychosocial health and stress (Carotenuto et al. 2013; Carter 2005; ITF Seafarers' Trust 2017; MacLachlan et al. 2012; Oldenburg and Jensen 2012). In response to this need, the primary aim of this study was to explore perceptions and experiences of well-being, resilience and stress amongst a sample of merchant seafarers and superintendents. Exploring perceptions of well-being, resilience and stress amongst this sample is required to inform organisational policies in the interest of improving working and living conditions for maritime workers. This study also aimed to explore perceptions of the pilot resilience programme and suggestions regarding the company's holistic health programme.

\section{Method}

\section{Participants and Procedures}

With the exception of superintendents who were office-based, participants were merchant seafarers, both officers and ratings/ crew, working in the shipping company's fleet. Participants worked on-board liquefied natural gas carriers, product oil tankers and crude oil tankers, on a global basis. The study comprised three research groups: (1) first interviews, comprising officers and ratings, including pilot resilience programme participants $(n=6)$; (2) one officers' focus group $(n=13)$; and (3) superintendents' interviews $(n=5)$. With the exception of the first interviews in which participants' job title was asked, demographic information, such as age and nationality, was not collected so that participants could not be identified.

Departments of merchant ships can be classified as: (1) deck department, responsible for managing the navigation of the ship, and handling cargo operations and berthing instruments on the ship deck; (2) engine department, tasked with the operation and maintenance of the machinery of the ship; and (3) catering department, responsible for meal preparation and housekeeping onboard (Bhattacharjee 2017). Officers supervise and manage all tasks related to the operating and maintaining of the ship; while ratings work under the supervision of officers across all departments, conducting essential jobs in the daily operating of the ship (Careers at Sea n.d.). Superintendents are responsible for providing leadership and guidance for ships' operations and are accountable for several factors including ensuring that ships operate safely, reliably and economically, and ensuring adherence to all legal and regulatory requirements and company policies regarding ship operations such as care of cargo, safety of navigation, and the health and safety of crew (Oil and Gas Job Search 2017).

English has been the lingua franca of the maritime industry for approximately the last century (Pritchard 2006). The interviews and focus group were therefore conducted in English; and were audio-recorded with the permission of participants. The first interviews were conducted between May and October 2015 via telephone and Skype as participants were on-board at the time of interview. The officers' focus group was subsequently conducted by the primary researcher at the Shell International Fleet Officer Conference, London, UK, in December 2015, as an event separate to the main conference meeting. The superintendents' interviews were also conducted by the primary researcher at this conference.

The first interviews were conducted to assess perceptions of the pilot resilience programme, in addition to exploring perceptions and experiences of resilience more generally. For these interviews, Random Purposeful Sampling was used (Onwuegbuzie and Leech 2007a), whereby cases were selected at random from the sampling frame consisting of a purposefully selected sample. Therefore, a list was obtained of individuals who had completed approximately half or more of the resilience programme; and individuals were then randomly selected from this list using an online random sequence generator. The company extended an invitation to these potential participants to be interviewed, and individuals then directly contacted the primary researcher regarding their willingness and availability to participate. The first interviews comprised six participants including two captains, two officers and two ratings (one female and five male participants). Three interviewees volunteered when invited to participate; two interviewees volunteered without prior invitation to be interviewed; and one interviewee was selected after directly contacting the primary researcher with feedback on the pilot resilience programme. Four of these interviewees had participated in the pilot resilience programme.

For the officers' focus group, Convenience Sampling was used (Onwuegbuzie and Leech 2007a), a form of non-random sampling whereby individuals are selected that are available and willing to participate. Officers were recruited at the Shell International Fleet Officer Conference, London, in December 
2015. During this conference, the primary researcher and the company invited officers to participate in a focus group. The officers' focus group comprised 13 officers (1 female and 12 male participants). Officers attending the conference were a mixture of captains, chief officers, chief engineers and second engineers, who comprise the top four ranks on-board and are all classified within the company as "officers".

For the superintendents' interviews, Convenience Sampling was again used. Superintendents working in the company's office in London were invited by the company to participate in an interview, and superintendents directly contacted the primary researcher regarding their willingness and availability to participate. A total of five superintendents were interviewed (all male). Superintendents in the company are ex-seafarers from the company's fleet, mostly former captains, chief officers, chief engineers and second engineers, who are office-based for approximately 2 years to assist with managing the vessels on a day-to-day operational basis to expand their experience.

Ethical approval for this study was provided by the Health Policy \& Management/Centre for Global Health Research Ethics Committee, Trinity College Dublin, Ireland. Employees of the shipping company participated in the planning and coordination of the study, and in jointly reviewing with the primary researcher the study design, analyses, findings and interpretations. However, while an initial invitation to potential participants to participate in the interviews and focus group was communicated by the company, which acted as a gatekeeper, the primary researcher independently conducted the qualitative analyses of the interviews and focus group, independently interpreted and discussed the findings, and independently wrote the original draft of this manuscript and decided to publish.

\section{Study Materials}

The primary researcher designed a semi-structured interview schedule for the first interviews, and a second semi-structured focus group and interview schedule for the officers' focus group and superintendents' interviews, underpinned by a review of the literature. The tools were first vetted with colleagues at the Centre for Global Health, Trinity College Dublin, Ireland, to acquire feedback on the scope, clarity and flow of questions (Ravitch and Mittenfelner Carl 2016). The tools were refined where appropriate. For example, the item "Do you have any personal experience in relation to resilience?" was rephrased as "Do you have any personal experience in relation to resilience or lack of resilience?"

Piloting of the tools was subsequently conducted. The primary researcher assessed the first interviews to evaluate the degree to which the questions were clear, understandable, capable of answering the research questions, and if any revisions were necessary (Collins 2010; Gill et al. 2008). As no significant refinement of the tools was considered necessary, this pilot data was included as part of the formal data set of the study (Plowright 2011; Ravitch and Mittenfelner Carl 2016).

For the first interviews, which comprised participants of the pilot resilience programme, the primary researcher administered a semi-structured, 31-item interview schedule. The interview schedule focused on perceptions of the resilience programme, general resilience and resilience on-board. The two participants in this group who were not participants of the pilot resilience programme were asked questions only regarding general resilience and resilience on-board. Additional file 1 provides the interview schedule for the first interviews.

For the officers' focus group and superintendents' interviews, the primary researcher administered a semi-structured, 20-item focus group and interview schedule. Questions focused on perceptions and experiences of well-being, resilience, and stress. One question asked participants for their suggestions regarding a wider (holistic) health programme at sea. Additional file 2 provides the focus group and interview schedule for the officers' focus group and superintendents' interviews.

\section{Data Analysis}

The primary researcher transcribed verbatim all data in full from recordings of the interviews and focus group. The method of constant comparison analysis, outlined by Elliott and Timulak (2005), was used to analyse the data. The data was therefore distributed into meaning units, namely, units by which the analysis was conducted. Broad headings, or domains, for organising participants' responses were identified. These domains were structured broadly during the beginning research stages through the interview and focus group schedules, but were developed primarily during data coding. Numerous organising frameworks were flexibly developed and tested until they were considered to appropriately and parsimoniously fit the data.

The meaning units were subsequently coded, or categorised, within each domain. Such categories emerged from the meanings in the meaning units. Formation of categories is an interpretive and interactive process, whereby the researcher labels categories similar to the actual language of participants, while also applying their own understanding and knowledge of previous theory and study findings (Elliott and Timulak 2005). Domains and categories were therefore identified primarily expost from data analysis; domains were structured broadly during the beginning research stages but were developed mainly during data analysis, and categories emerged solely from the data.

\section{Findings}

Presented below are domains and categories that were identified from data analysis of the study's three research groups, i.e. (1) first interviews, (2) officers' focus group, and (3) superintendents' 
interviews. Domains and categories are not ordered with regards to importance nor do they suggest any hierarchy.

\section{(1) First Interviews}

Domains and categories for the first interviews are presented schematically in Fig. 1.

\section{Workload}

Stress and Pressure Participants indicated experiencing stress and pressure, as exemplified by one captain's observation:

I am in the shipping profession for more than 26 years, so what it was earlier as today, there is a total change in this whole profession. Even now, we are very much under stress and like before people used to get time to unwind, you know, and when they used to go ashore and all that. Today in the shipping world, we hardly get to step ashore. In the three months that we are on-board, we are not allowed to even step on the gang (P2 [participant 2]).

\section{Safety}

Open Reporting and Intervening are Promoted Numerous participants suggested that intervening was encouraged. For example, a captain reported directing his crew to talk to seniors when they deemed work as unsafe:

I tell them for everything you should have situational environment. Before we engage our hands, our minds, you know, to work so that we assess the situation, and if we feel it is unsafe you know, then we should be in a position that they should come and talk to the supervisors ... if we see such things and we immediately report, $\mathrm{OK}$, then we save somebody from getting injured (P2).

Positive Psychology Improves Safety A number of participants reported using positive psychology to support safety. For example, an officer asserted that positive psychology was emphasised in safety programmes: "Positive psychology is always emphasised. We do have some other safety programmes where we always make sure to commend the person when they are doing something right, something good, you know, and actually it helps" (P3).

\section{Social}

Separation from Family Causes Stress A number of participants reported stress caused by separation from family, as exemplified by a captain's comment: "You sometimes you feel helpless completely. You cannot do anything because you cannot jump from your boat and swim to home" (P1). Another captain alluded to stress experienced by his children:
Fig. 1 Domains and categories for first interviews

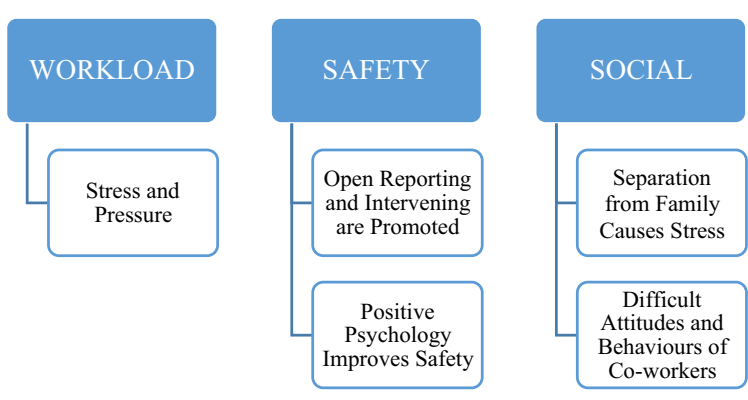

RESILIENCE PROGRAMME CRITICISM

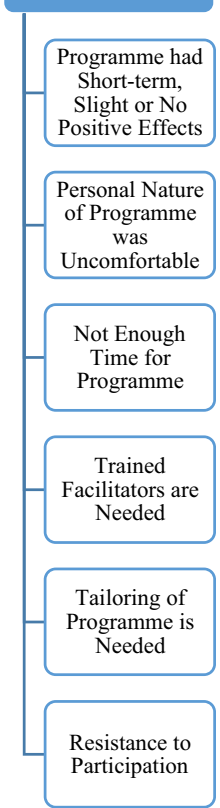


When there are crises at home or some issues at home, they told me you are never there, but then I tell them that I am not like, you know, all the other parents ... in a year, six months I am with them 24/7 (P2).

Difficult Attitudes and Behaviours of Co-Workers A number of participants reported difficult interactions with co-workers, as illustrated by one rating's observation: "If I try to discuss or negotiate with senior officers or managers, and they act differently or they react in an unprofessional manner ... because it is rather stressful when being faced with that position" (P4). Correspondingly, another rating reported his experience as follows: "There are really people that's very, very, very difficult to deal with, you know, this, you know, this character that, unbecoming character, and that gives you torment every time" (P6).

\section{Resilience Programme Acclaim}

Programme had Positive Effects All four participants of the resilience programme who were interviewed reported positive effects of the programme. For example, a rating asserted that the programme strengthened understanding and tolerance of colleagues:

We see a different side to the person we work with that we don't normally engage with, and then we understand the person more, and when we understand the person more, and we understand his background or his way of thinking, we are more tolerant of this person (P4).

Willingness to Continue Programme Each of the four resilience programme participants asserted their willingness to continue with the programme. For example, a captain remarked: "I have no issues to participate in this, and wherever I am I will take it forward" (P2). Furthermore, when asked if he would like to participate in further programme modules, a rating replied: "Yeah sure, I would love to. I would really, really love to" (P4).

Positive Psychology is Important A number of participants spoke of the value of positive psychology on-board, as exemplified by one captain: "In shipping I believe, you know, we have to have that you know positive thinking ... if you show positive attitude and you always believe in positive things, so I motivate my team that way" (P2). Similarly, a rating outlined that positive psychology could be useful to alleviate stress: "Positive psychology ... when you are on-board the vessel, away from family and friends and your loved ones, can already be stressful enough ... so any positive psychological aspect would definitely help [laugh]" (P4).

\section{Resilience Programme Criticism}

Programme had Short-Term, Slight or no Positive Effects Although participants reported positive effects, they also indicated short-term, slight or no positive effects of the programme. For example, one captain described the effects of the programme as follows: "In moment you are participating the resilience programme, you feel better, you feel more relaxed and you understand the others much more than before, but for how long it is going to stay with you is the problem" (P1). He asserted: "There is some slight improvement but you know in the twelve modules, in twelve hours, you cannot change your character, you cannot change your habits" (P1).

Personal Nature of Programme was Uncomfortable Numerous participants contended that the personal nature of the programme was an uncomfortable experience. As expressed by a captain: "I remember it was a presentation of the third officer who actually described his problem and how he beat his crisis that time, and I did not like it because we went too deep inside of his private life" (P1). Similarly, a rating asserted: "The module could be a little bit too much on the heart, where you've to express your feelings or more intimate personal ambitions ... for this type of behaviour, hardheaded type behaviour, they don't tend to accept it well” (P4).

Not Enough Time for Programme Several participants highlighted a lack of time for implementation of the programme, as illustrated by a captain's comment: "This is the shore based programme ... but here you need to know this vessel is running 24/7" (P1). Another captain referred to lack of time for the programme due to other training programmes and duties:

Life on-board is very hectic you know and everybody has all their designated duties... I have to squeeze in this resilience meeting ... one normally it takes thirty to forty minutes so you know then, that was one thing which people are against (P2).

Notably, an officer reported more time for the programme when ships were on longer voyages: "If we on some longer runs from Qatar to Asia or Qatar to Europe somewhere, then there is no problem with the resilience modules and other vessels do it" (P3).

Trained Facilitators are Needed Numerous participants indicated that people who had been trained to facilitate the programme were required. For example, a captain remarked: "We do not have a proper facilitator on-board, because this programme was just sent on the CD and then that's it" (P1). Correspondingly, an officer stated that participants would have greater respect for the programme if it was delivered 
by a trained facilitator: "A trained facilitator who will be able to introduce resilience models. I think that people would take it more seriously if we would have somebody on-board specifically for that role" (P3).

Tailoring of Programme is Needed A number of participants recommended adapting the resilience programme to the onboard context, as exemplified by a captain:

One small difficulty to present in the same time ... because on-board of course we have different nationalities, different rank with the people and with also with the different education ... different nationalities which their mother language is not English like it's not for me, so there is a lot of un understanding of the wording (P1).

Another captain suggested using shipping-specific examples: "Put some shipping, what we do on the ship for day-to-day, or even if you can show that, that will help guys to you know relate" (P2).

Resistance to Participation Several participants indicated that there was resistance to participating in the programme. For example, one officer specified that people viewed the programme as another safety programme: "They do resist because it's like 'oh one more safety initiative, what is this now?'” (P3). Although not a programme participant, another officer indicated that the company did not provide monetary incentives for programmes, which reduced people's motivation: "What most people want is incentives if they want to do something right, if they want to teach something ... they want physical objects or cash ... so these people aren't really too motivated" (P5).

Fig. 2 Domains and categories for officers' focus group

\section{(2) Officers' Focus Group}

Figure 2 presents domains and categories for the officers' focus group.

\section{Workload}

Stress and Fatigue Officers reported experiencing stress and fatigue. They indicated working for 10 hours or more daily, as illustrated by a participant's comment: "I average over, somewhere between 10 and 11 hours a day for three to four months" (P5). One participant emphasised mental health problems due to stress:

P11: ... they're just dumping it on you. This is your job. You're 24 hours at sea. We're paying you for being at sea 24 (P6: Yes) hours. We're entitled to ...

P6: Call you anytime.

P11: Yep ...

P9: Yeah.

P6: Yes.

P11: ... how we manage that stress, how we manage our mental health is this big problem worldwide.

Officers also reported more stress in recent years:

P9: Yeah, time on-board was different (P1: Yeah). There was no Internet, but there was enough booze. There was enough time in the port, you know, so.

P1: Yeah. You didn't have a stressful trip like that.

Notably, one officer indicated experiencing less stress when ships were on longer voyages:

Sometimes we have long voyage and there is not too many emails. You know, everything is going

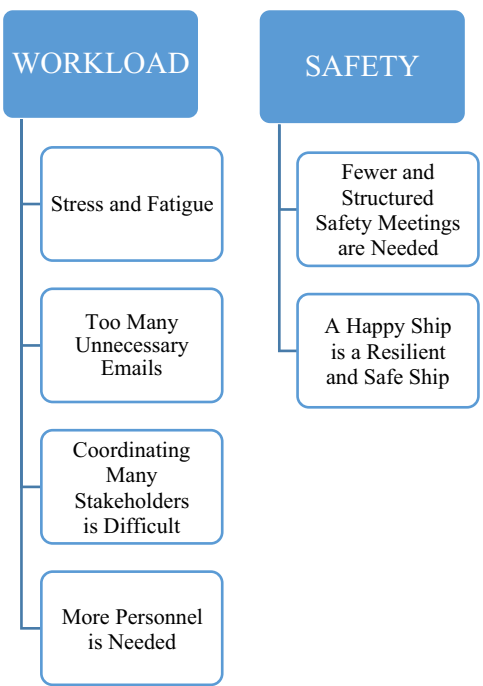

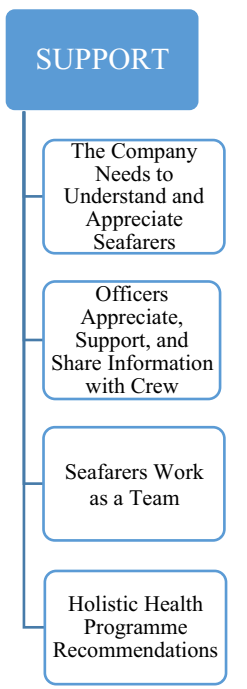

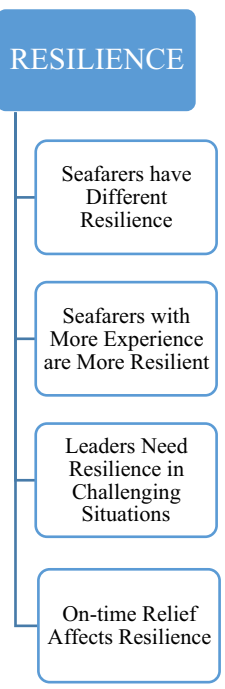


smooth, so I used to go in the gym, and I really enjoy for one and a half hour. I really enjoy that, you know (P8: Mmm), but when I'm you know like seven days stuck in the office and running like a yoyo up and down [laugh], like you know, so I feel also very bad mental (P9).

Too Many Unnecessary Emails Officers highlighted an excess of emails being sent from the shore office to vessels, as the excerpt below exemplifies:

P12: ... you used to go and do your round trip ... contact the charters a couple of days out and you just have to go in ... just before, you know, you might have a couple of telephone calls or emails, but now it is like up to fifty a day come through emails ... there's a lot more stuff that comes through to the ships that never used to and probably really doesn't need to ...

P7: Mmm.

P11: Instead of shore being a support mechanism now, they can consider you as a 24-hour work stations.

Coordinating Many Stakeholders is Difficult Officers reported difficulty with coordinating many stakeholders, as exemplified below:

P9: ... this is not easy for us ... on-board there's so many, you know, influences from others, on-board, you know, to us.

P2: With distractions ...

P9: Distractions from everywhere ... We have our office who is giving us orders. We have a charter who is giving us orders.

P2: ... port operators ...

P1: Like you have to balance everything on top.

P2: ... managers, so many people you have to coordinate.

More Personnel is Needed Officers expressed the need for more personnel:

P7: ... we have no reserve capacity ... You know, forty years ago, we had fifty, sixty people on the ship ...

P2: and we don't have any stand-by ...

P7: ... If one person was down, there was a lot of people to cover him (P9: Yeah, yeah, yeah, yeah), but we're down to no capacity, no reserve ...
P5: And then the thing is though is your size of the ships are larger.

P7: Huge ...

P9: Yeah, yeah.

P2: 'Cause we're one of the largest LNG [liquefied natural gas] ships which is floating (P9: Yeah ...), and running by only 30 peoples on-board.

P6: ... some ships have extra people. Some ships don't have them.

\section{Safety}

Fewer and Structured Safety Meetings are Needed Officers recommended reducing safety meetings on-board, as illustrated by a participant: "It's also reducing unnecessary meetings on the ship because whenever something happened somewhere, they say 'OK collect all crew. Let's do a meeting'" (P3). Officers also recommended structured safety meetings:

P12: ... a structure (P3: Yeah) would be a lot more helpful (P9: Yeah, yeah) and beneficial than just say "have a safety stand-down" ...

P2: Yeah, for stand-down, you send some guidance; "you do this, do that". Then we can do that ... Everybody is working a different way and different places (P9: Of course), and you just put everything down and come back here. This is creating more stress.

A Happy Ship is a Resilient and Safe Ship The officers asserted that when seafarers were happy, safety and resilience were strengthened, as illustrated below:

P8: Yeah. A happy ship's a safe ship.

P9: Yes, definitely.

P2: It affects the performance of the people (P9:

Definitely), affects the safety of the ship, safety of the personal environment and everything.

P3: ... if the team is more happy, it will be more resilient.

\section{Social}

More Socialisation is Needed According to the officers, socialisation on-board had reduced due to the Internet, as illustrated by an officer's observation: "The other thing that we've had break down with the advent of Internet is the community that we used to have" (P5). The officers reported a lack of social support, suggesting for example: "When I have a problem from home, and then you looking for somebody on the ship to talk with, everybody's closed in their cabins, so 
nobody, there is no more social life" (P3). One officer asserted that seafarers were struggling with their choice of profession:

There's no fun in our job anymore. All we're left is the residual stress of work, and ma'am we're really struggling to find out what are we doing here, you know at work? ... we're sort of struggling with trying to get a life because we spend over $50 \%$ of our life at sea with our mates ... so this is a little bit sad if you're not having a life at sea, if it's just a workplace (P11).

Alcohol Prohibition Reduces Socialisation Officers asserted that authorisation of alcohol in the past provided opportunities for socialisation, as illustrated below:

If you still had your two beers a day before people run off to the Internet, they would come in after the hot day (P9: Yeah) on deck or down in the engine room and have a couple of beers, have a chat, get a lot of this stuff off their chest 'cause there's no, as you said there's no family, there's no community on-board (P12).

More Shore Leave is Needed Participants spoke of restricted shore leave in recent years. One officer proposed that seafaring had shifted from a lifestyle to a job:

P11: ... Going to sea used to be a lifestyle decision once, so within your lifestyle you had the social network, the professional of your trade, and that was all rolled into one. Now going to sea is a job, and the company has, they're grasping with trying to get all the benefits of having a lifestyle person on-board, and demanding it's your job, whereas the employee, we've lost all the lifestyle choices. We've lost all the lifestyle satisfaction, going ashore, having a beer with your mates.

P5: There is no going ashore.

P8: Yeah.

P11: Yeah. There's no fun.

Increased Communication with Family is Stressful The officers highlighted that increased communication with family was causing stress, as exemplified below:

Father tell me one day, he goes when he went to sea, there was no communication at all. He'd leave. He goes he'd go to sea. His wife would have a drama. He'd never know about it. She'd deal with it; have another drama; she'd deal with it. Then he'd come home and hear all about it and he was at work just doing his thing, not having to think about it. Day of Internet, now we have to hear about all their problems at home and so we're stressing sort of about (P7: Yeah) their issues that we can't do (P8: Yeah) anything about [laugh] (P13).

\section{Support}

The Company Needs to Understand and Appreciate Seafarers Participants discussed the need for the company to be more understanding, as expressed by an officer:

These are seafarers running companies, and now they have forgotten their roots. They need to get back there and understand where we've come from because if there is, if it continues like this worldwide, there will be a day where seafarers will say "we'll take the shores" (P10).

The officers also expressed the need for more appreciation and recognition:

P2: ... it's a thankless job. You do a hundred good jobs, OK. You do one mistake, then you are totally wrong ... P1: But it is a profession which is not, what do you call (P6: Yes) (P9: appreciate) recognising and appreciate.

Officers Appreciate, Support, and Share Information with Crew The officers reported appreciating, supporting, and sharing information with crew, as exemplified below:

P5: I pat my guys on the back ... I say "good job" ...

P2: And to recognise the people for their good work ...

P7: So simply smile and say "hello".

P8: Recognise if there's something not right with someone.

P9: Recognise yeah ...

P8: Just walking round, you can generally get a feel (P5:

Oh yeah) (P3: Try to help whenever you can), sort of, right there's something wrong with you.

Seafarers Work as a Team Officers emphasised the importance of seafarers operating as a team, as illustrated below:

P1: ... out at sea it's more of a team resilience that you really look into because (P7: Yeah) the team gets you through ...

P5: ... If you depend on one guy, then you're toast. 
The officers articulated the importance of every person on-board:

P9: This is how I explain to my guys: We are wheels. I am captain, my responsibility higher, I am big wheel. He is mastman, he is smaller wheel, but he's also turning, and we are all turning. If his one is not turning properly, all other wheel will start suffering ...

P1: Everybody's important on-board.

Holistic Health Programme Recommendations When asked to provide recommendations for the company's holistic health programme, the officers emphasised that the programme would be an additional job. They suggested implementation of the programme by health professionals instead. Notably, one officer reported having had more time for the pilot resilience programme when on a longer voyage:

P1: Yeah. It add another task, another job, which we'll have to take care of ...

P5: I mean this is the problem ...

P12: See recently we've had actual health professionals come out and do health assessments and training and exercises and gym programmes on-board and fitness assessments and that.

P10: If you could arrange a (inaudible) team going vessel to vessel and implementing it and educating us, it would be great ...

P6: ... when we start resilience, we went to (country), so it was (country) and then we manage in these two months to do a lot. OK because (country) is a long voyage and it was $\mathrm{OK}$, I mean quiet most of the time so, but it's very difficult for us on-board to do this in other circumstances.

The officers recommended adapting the pilot resilience programme to the on-board context:

P6: And we have to be more resilient. Why? Because (P9: Yeah) resilience programme came on-board. We have to make it on-board. We have to do it on-board because it was sent to us, and then we have to be more resilient to do it without interrupting or interfering too much with the ship's life, with the resting hours (P9: Yeah), with working hours, with everything ... any system made for the shore side, it will not fit on-board ...

P9: It doesn't mean that it will work on-board, yeah?

P3: It's different.

P6: It's must be adjusted, must be trimmed ...
Of note, as an additional suggestion in relation to support for seafarers, two officers recommended the introduction of an Employee Assistance Programme in the company:

P7: ... an employee assistance programme, which is usually like a toll-free phone number that basically gets you to psychologists, you know, professionals that help with at least directing you to resources ...

P5: the assistance you need.

P7: It wouldn't use the resources that we are short on the ship already ...

P5: and it's no extra burden. It'd actually sort your problem probably.

\section{Resilience}

Seafarers Have Different Resilience The officers asserted that resilience differed across seafarers, illustrated by an officer's example: "Somebody get hurt, and then you see these different people act different, so somebody will be composed and he will start to attend this person, and somebody will run around" (P6). They recommended providing more training for people with low resilience, asserting for example: "Some people needs more training or more experience because I was now with a good team, and one, I mean no names, no positions, one team member was still ... was very low resilience" (P6).

Seafarers with More Experience are more Resilient Participants suggested that resilience increased with seafaring experience, and that they relied on experience, as demonstrated below:

P7: Yeah. I think we always revert to what we've seen before in any situation.

P4: Correct.

P7: Any stressful situation, you'll always hear most of us talking about our last ship, and what happened on that ship, and comparing it to whatever problem we face ... P5: ... We have to fall back on experience (P9: Yeah) to help us through today ...

P1: Experience is something that you can't buy off the market can you? ...

P2: ... with experience, the resilience gets up.

Leaders Need Resilience in Challenging Situations Officers indicated that leaders needed to be resilient in difficult situations, specifying for example: "If the leader doesn't is not resilience to the situation, everybody else will you know be in a panic or, so the most important is that actually the leader stay you know like calm" (P3). Another officer recalled: 
No-one actually recognise that there was a problem because you know I just put a smile, and if I start shouting, if I start panicking, I will just pass it to them as well you know (P8: Yeah), so I was just trying to you know to make the laugh, jokes you know and we solved the problem (P9).

On-Time Relief Affects Resilience Participants emphasised that on-time relief impacted on resilience, asserting for example: "On-time relief will help to build up the resilience with the team because if you work longer time, then your resilience comes down" (P2). Notably, one officer suggested that seafarers no longer wanted to be at sea due to the occupation transitioning from a "lifestyle" to a "job", which affected on-time relief:

Going on what (participant) said about the lifestyle rather than our job, that's I think sort of a big part to play of people not turning up ... and then people getting stuck on for longer because that's just a job now, and no-one wants to be there, like no-one really wants to go and do the job, but when it was a lifestyle, people wanted to go, you know. They were happy to go back to work, and I think that's gone (P12).

\section{(3) Superintendents' Interviews}

Domains and categories for the superintendents' interviews are presented schematically in Fig. 3.

Fig. 3 Domains and categories for superintendents' interviews

\section{Workload}

Stress and Fatigue Superintendents reported that seafarers experienced stress and fatigue, exemplified by a superintendent's reflection:

You get three months on, three months off, but the workload in that three months is immense ... you go home from that situation drained because you're on a 24 hour call out ... you may get your night's sleep. Quite often you do. Sometimes you may not get it for a long period ... there are times that it all builds up (P3).

Notably, two participants reported experiencing stress as superintendents, asserting for example: 'I didn't know which way to turn, work-wise. There was pressure from the ships, from the owners, from the charterers, from my bosses, from the company that manufacture the equipment" (P5).

More Time to Carry out Jobs is Needed Superintendents emphasised that seafarers required more time to complete jobs, as exemplified below:

You've got to manage it, and yet those of us at sea know in that 24 hours, it basically means everybody working flat out. You need more time. If I had more time for each job, it would mean I could rest people sensibly. If they decided not at that time to send a contractor if it wasn't particularly required, or not do all the operations at the one go, and it gave you time. Time is always the big stress factor. You just don't have the time (P3).

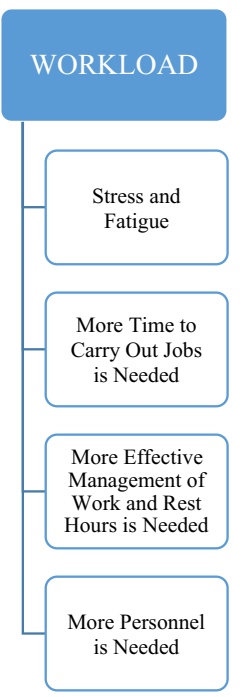

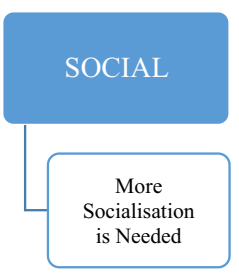

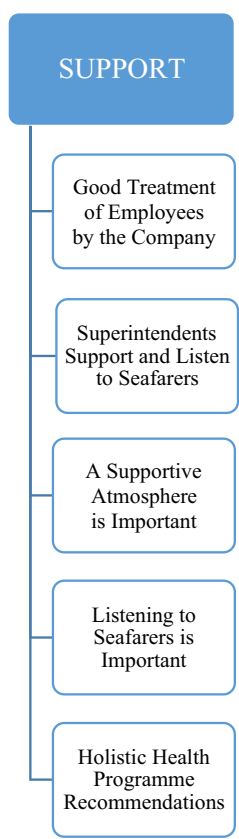


More Effective Management of Work and Rest Hours is Needed Superintendents reported the need for more effective management of work and rest hours on-board, suggesting for example: "We must work towards the working hours and rest hours of the people, of the crew, because there are so many times when crew is working, you know, more than what they can stand" (P4). One superintendent described seafarers working for up to 16 hours per day:

I have seen people working from seven in the morning 'til eleven in the evening, so you're working for 14, 15, 16 hours a day ... [the company] will never propose anybody to work beyond five ... but there have been scenarios where people have had to do extra work because of time pressures, port arrivals (P1).

More Personnel is Needed Participants recommended an increase in personnel on-board, as exemplified by a superintendent's account: "We're very, very tightly manned, and although we may have extra people compared to the competition, it just feels that everybody's doing so much more and rushing into it" (P2). Another participant specified:

Everybody would like to have more officers at sea, more personnel, but I don't think it's ever going to happen ... you couldn't remain competitive and do it. I mean everybody knows that. Each chance they get, there are people who are at sea now who say "well give us an extra officer", but it's not going to happen [laugh] (P3).

\section{Safety}

\section{Accountability for Health and Safety Causes Stress} Superintendents contended that seafarers experienced stress due to accountability for health and safety. For example, a superintendent asserted:

If they have an incident ... the consequences are really sometimes we say "just", but in some ways it can be harsh for the people ... this anxiety is always there that what if something goes wrong and what if you or your fellow or if I'm on-board if I'm held accountable for this? (P4)

Another superintendent proposed:

Maybe someone did get sacked because they'd had an injury, but it wasn't because of the injury they got sacked. It was because of the events that led up to [laugh] that injury or surrounding that injury, but they don't see that. They see, you know [gasp] if I cut my finger, I'm going to get sacked ... and to try and undo that with so many people is absolutely ... a nightmare ... The only way you can do it is just keep demonstrating every time that there's a fair process (P5).

Responsibility of Seniors for Safety Superintendents discussed the responsibility of seniors for safety on-board. For example, a superintendent recalled an incident whereby a colleague under his supervision was injured:

That was very, very difficult for me to accept that because it was under my care, and how could this happen? ... it was many years ago so I'm not really sure how long it affected me but even now I can remember that incident that happened ... so that was a significant, like emotional experience (P2).

Well-Being and Resilience Affect Safety Superintendents asserted that safety was impacted by well-being and resilience, as exemplified by a participant's assertion:

To be safe in that kind of environment where even walking down the stairs could be potentially life threatening because it's all steel ... you need to be focused so in that respect your physical and mental well-being always needs to be perfect (P2).

\section{Social}

More Socialisation is Needed Superintendents reported that more socialisation was needed on-board. They spoke of reduced socialisation due to the Internet and restrictions in relation to alcohol and shore leave, as illustrated by one superintendent's account:

If we'd have a tough day, a tough week, even when the Internet came, everybody would be in the bar after work. We'd have a couple of beers ... you would talk about everything, and that engagement as a team now has been lost on a lot of ships ... the atmosphere on-board is what makes it, helps people to work in that environment (P5).

A superintendent suggested restoring socialisation by addressing it at the senior level: 
This probably needs to be addressed at the senior level, where we talk to the captains and the chief engineers, saying “... let's see if we all can get maybe once every two weeks get everyone together, get a game organised or get a movie organised" (P1).

This participant also suggested celebrating festivals on-board: "Put that in front of captains saying that 'let's see if we can do festivals as well' because there's so many nationalities. There's so many important festivals ... That does help you know boost the morale" (P1).

Notably, two superintendents indicated that ratings had a better social life than officers due to ratings' fixed meal times; their homogenous nationality; and the set-up of their mess onboard. As stated by one participant: "For the crew, for the Filipino lads ... they get together more as a group ... The social interaction is gone at officer level" (P3).

\section{Support}

Good Treatment of Employees by the Company Superintendents provided examples of good treatment of employees by the company. For example, one participant contended:

Shell's got their hands on in terms of well-being much better than other shipping companies because if you go to other shipping companies, you've got contracts for six months at a time. That tends to take you away from everything that's happening on land, and also I believe Shell was one of the first companies to come on with the Internet (P1).

\section{Superintendents Support and Listen to Seafarers} Superintendents reported supporting and listening to seafarers, as illustrated by a superintendent's comment:

Whenever I speak to them, they always get, you know, "how are things? How's the family? How are you doing? How's things on-board? Is everyone OK?", so I always start a conversation with that, even if it's about something completely different because that, it gives me an idea of how they are, if there's any issues ... if there is an issue with anybody, they'll get as much support as I can give them (P5).

A Supportive Atmosphere is Important Superintendents emphasised the importance of a supportive atmosphere onboard, specifically a team environment underpinned by trust, support, and approachability. For example, a superintendent suggested leadership courses for seniors on soft skills such as building trust and support:

In a shore-based organisation, as you rise up the ranks, there is that formal mentorship and relationship. On a ship, your boss, your colleagues, they keep on changing ... so it's very difficult to build that relationship or to build that trust and take it forward and to have that mentorship going, so people land up in roles and they don't have the skills to manage the soft skills, to handle the softer parts of those roles, managing other people or situations or conflict, and I think if we have those courses for the seniors ... it'll help not only those individuals, but it will also help them to treat the juniors better ... a course in just basic leadership ... for them to understand that the importance of building trust and supporting each other (P2).

Listening to Seafarers is Important Superintendents highlighted the importance of listening to seafarers. For example, one superintendent stated:

Most important is considering well-being of people and probably listening to the guys, what do they want, and how they will do it. It is not necessary that you act on it, but just listening to them probably gives them a morale boost. OK there's somebody at the other corner who's listening to me, and in that sense if something adverse does happen tomorrow, he'll probably come and share with you, and it'll be easier for him to overcome it, so maybe that might give them more resilience (P1).

Holistic Health Programme Recommendations When asked to provide recommendations for the company's holistic health programme, two participants suggested a social aspect in the programme, suggesting for example: "Socialising, introducing game sessions and things like that. We can probably put that in front of captain and chief and tell them 'OK let's get this done" (P1). Two superintendents suggested a dietary component in the programme, as asserted by a participant: "Do you change the food? ... for instance we did away with alcohol and now we're offering people free soft drinks" (P3). One superintendent recommended simplicity in the programme design: "Making it very, very simple. Some of the guys don't have great English ... If you want them to understand it, it needs to be like quite catchy and simple" (P5). Furthermore, he suggested integrating the programme into seafarers' daily lives: "If it can be integrated into their daily lives on-board a ship, that would be fantastic because then 
they would do it without any disruption ... say, you know, getting them to interact for fifteen minutes in the morning" (P5). As a further suggestion related to support, he recommended the availability of counselling:

Support functions, you know like counselling or anything like that. Maybe it needs to be a bit more advertised ... because I'm sure there are a lot of people that struggle, that don't feel comfortable talking to people in the team ... it's not obvious that there is [pause] professional help (P5).

\section{Discussion}

The primary aim of this study was to explore perceptions and experiences of well-being, resilience and stress amongst a sample of merchant seafarers and superintendents. The discussion, presented below, is not intended to be exhaustive, but to examine several issues arising from the findings with respect to a review of the literature. Findings of this study are interwoven by two critical themes: Recent changes in the working and living conditions of seafarers, and their preference for explicit organisational justice.

\section{Pilot Resilience Programme and Holistic Health Programme}

With regard to the first interviews, while participants of the pilot resilience programme reported positive perceptions and experiences of the programme, they also expressed criticism. Many of these criticisms were underpinned by the need to adapt the programme to the unique on-board context. Specifically, numerous participants reported that the personal nature of the programme was an uncomfortable experience on-board; a lack of time for the programme; and the need for trained facilitators on-board. Furthermore, the need to tailor the programme was emphasised in relation to addressing its concurrent delivery across diverse nationalities and ranks, and the importance of simpler English and shipping-specific examples. Notably, change of crew on-board was discussed as an obstacle to assessing the impact of the programme and to programme continuity.

With respect to the officers' focus group, officers recommended more training for seafarers with low resilience; however, they emphasised that the company's holistic health programme would be an additional job on-board. They also recalled their need to be more resilient to implement the pilot resilience programme without interrupting working hours. Indeed, these assertions indicated that, paradoxically, the officers viewed health programmes as a source of stress on-board.
The officers suggested implementation of the programme by health professionals instead.

In relation to the superintendents' interviews, when asked to provide recommendations for the company's holistic health programme, superintendents suggested the inclusion of a social aspect and a dietary component in the programme. Of note, a participant recommended a simple programme that used examples, which could be integrated into seafarers' daily lives.

Accordingly, both the first interviewees and officers referred to a lack of time to implement the pilot resilience programme. Of note, two officers reported more time for the pilot resilience programme on longer voyages, while another officer reported less stress on longer voyages; thereby indicating that delivery of health programmes during longer voyages could facilitate their implementation.

Notably, as the seafaring workforce is isolated and dispersed, online or computer-based psychosocial interventions and training may be a valuable approach to health programmes for this population. Numerous Internet-based interventions have been developed and tested for common psychological disorders, and research indicates that these treatments frequently lead to similar outcomes as face-to-face psychotherapy, alongside being cost-effective (Andersson and Titov 2014). For example, online positive psychology interventions may be accessible, inexpensive, and scalable, with the capacity to reach a diversity of populations (Bolier et al. 2014; Drozd et al. 2014; Redzic et al. 2014).

\section{Recent Changes}

Stress was reported by all three participant groups, i.e. first interviews, officers' focus group, and superintendents' interviews. For example, officers reported more stress in recent years and indicated working for ten or more hours per day. This finding is consistent with the literature, which emphasises a variety of psychosocial and physical stressors experienced by seafarers, including fatigue and sleep deprivation, separation from family, loneliness, multinational crew, physical demands, and lack of recreation (Bal Beşìç̧̇ et al. 2016; Carotenuto et al. 2012; Comperatore et al. 2005; Hystad and Eid 2016; Jepsen et al. 2015; Oldenburg et al. 2013; Oldenburg and Jensen 2012).

Good treatment of employees by the company was discussed by superintendents; however, participants indicated recent changes in the company and profession. Such economising by the company for which the participants worked is a microcosm of cutbacks that have occurred across the maritime sector - whereby the drive for profitability in the shipping industry has further led to decreased personnel onboard, longer working hours, and shorter turnaround schedules in ports (Rydstedt and Lundh 2010). As indicated above, one captain asserted: "There is a total change in this whole 
profession. Even now, we are very much under stress". Similarly, a superintendent reported more stress in recent years: "There is a lot of stress on the seafarer nowadays". One officer communicated changes in the occupation by specifying: "There's no fun in our job anymore. All we're left is the residual stress of work, and ma'am we're really struggling to find out what are we doing here, you know at work?" His observation indicated that he may have been questioning his choice of profession - and indeed his identity as a seafarer. As suggested by Hult and Ljung (2012), the seafaring occupation may strongly influence identity creation. Similarly, MacLachlan (2017a, p. 4) specifies that "with larger ships, greater mechanisation and reduced manning levels, more is required from seafarers and there are fewer outlets for the sort of affiliation that sustains both a sense of collective identity and individual worth and support".

Both officers and superintendents emphasised the need for more socialisation. Officers asserted that a decline in socialisation had resulted from the prohibition of alcohol on-board. Moreover, several officers and superintendents reported that the introduction of the Internet had impeded socialisation. Officers also reported the need for more shore leave. Accordingly, participants indicated experiencing stress, alongside fewer opportunities to relieve stress in recent years due to reduced socialisation and shore leave. These findings are congruous with the literature, which highlights social isolation on-board (Alderton et al. 2004; ITF Seafarers' Trust 2017; Mission to Seafarers 2018; Thomas 2003), alongside a lack of shore leave (Clare 2015; Kahveci 2007; Kantharia 2017; Oldenburg and Jensen 2012; Shoretoo 2015; Walters and Bailey 2013). Notably, the Maritime Labour Convention, in recognition of the importance of shore leave, specifies that "seafarers shall be granted shore leave to benefit their health and well-being" (Regulation 2.4) (ILO 2006, p. 33). Furthermore, seafarers' right to shore leave has received extra protection by amendments to the Convention on Facilitation of International Maritime Traffic (FAL Convention), entering globally into force as of January 2018 (IMO 2018).

\section{Organisational Justice}

The importance of organisational justice was an emerging critical theme from the qualitative data. Recent changes in the working and living environment on-board, such as reduced socialisation and shore leave, may also be a source of perceived inequity and organisational injustice. As suggested by Adams' (1965) theory of inequity, while an individual usually makes social comparisons with another person to determine if inequity exists, an individual may also make comparisons with oneself in a previous job, comparing present and past inputs and outcomes and assessing if the exchange with an employer, present or past, is equitable. Seafarers, particularly those long enough in the profession to have witnessed significant change in recent years, may therefore perceive inequity when comparing working conditions now to those of the past. As expressed by one officer:

"Now going to sea is a job, and the company has, they're grasping with trying to get all the benefits of having a lifestyle person on-board, and demanding it's your job, whereas the employee, we've lost all the lifestyle choices".

Furthermore, a number of issues highlighted by participants may be symbolic of injustice, with this perception potentially causing more widespread frustration and discontent than necessary. For example, officers communicated the need for more appreciation. Lack of recognition for effort and performance at work can lead to perceptions of injustice (Furnham 2012). Simple, symbolic actions - such as expressions of gratitude by a company - can strongly signal to employees that they are valued (MacLachlan et al. 2010).

In the first interviews, a number of participants reported their perception of difficult interactions with co-workers. Notably, interpersonal justice, a form of interactional justice, signifies being treated with respect in the workplace (MacLachlan et al. 2010). Importantly, job satisfaction is likely to decrease when employees perceive organisational injustice (Schultz and Schultz 2016). Indeed, organisational justice significantly influences job satisfaction and dissatisfaction, as well as intent to leave and broader well-being (Furnham 2012).

\section{Limitations}

\section{Generalisability of Findings}

The focus of this study has been on a single company engaged in bulk hydrocarbon transport. Other shipping companies or cohorts of seafarers do not necessarily share the attributes of this company, including the routes and distances travelled, routines and procedures on-board, and the multinational nature of the company and its high public profile, which create a specific working and living environment on-board. It is important to caution against extrapolating from one study across the maritime industry, which constitutes a wide scope of employers, flags, States, ship types, contract types, and recruitment and remuneration practices. Furthermore, the study's sample was mostly comprised of participants occupying higher positions in the company including officers and superintendents, with interviews conducted with only two ratings; however, notably, focus groups with Filipino ratings in a related study are reported elsewhere (McVeigh and MacLachlan 2019). 
This study did not comprise a large, representative sample. As emphasised by Onwuegbuzie and Leech (2007b, p. 238), "only when relatively large representative samples are utilised should qualitative researchers attempt to generalise findings across different populations (i.e. population generalisability), locations (i.e. ecological generalisability), settings, contexts, and/or times (i.e. temporal generalisability)". Unless a study comprises a representative sample, qualitative research must therefore refrain from generalising beyond a sample to a particular population (Onwuegbuzie and Leech 2007a). However, notably, as suggested by Corbin and Strauss (2015), "in qualitative investigations, researchers are not so much interested in how representative their participants are of the larger population. The concern is more about representativeness of concepts and looking for incidents that further develop them". Generalisability in qualitative research may therefore best be approached in terms of "conceptual generalisability" (Green and Thorogood 2005).

\section{Social Desirability}

Although confidentiality was assured to participants, participation in the interviews and focus group occurred in a work context, and participants may therefore have been less candid than they may have been in a different context. Participants may have deliberately or unintentionally given socially desirable answers (Spector 2004), including biased responses to reflect the desired answers of the company in which they worked. For example, as communities in LMICs are highly dependent on the income of seafarers (Borovnik 2011), ratings may have been vigilant about endangering their jobs by openly speaking about their work experiences; however, participants seemed to be quite candid in their responses, as evidenced by the findings above.

\section{Conclusion}

Although depression and other forms of psychosocial distress may be experienced individually, their causes are multifaceted and cannot be addressed only at the level of individual functioning. Importantly, factors that influence the well-being and performance of maritime personnel are imbedded at several levels of work, including the task, individual, team, organisation and industry (MacLachlan et al. 2013). We must address causes of perceived injustice at the organisational and industry levels, alongside supporting the capacity of individuals to cope with challenging situations (MacLachlan 2017b). Therefore, while psychological resilience training in the shipping sector could support safety and strengthen the well-being of employees (March on Stress 2013), a working environment that is experienced as supportive and just is crucial for individually focused psychosocial interventions to be optimally applied (McVeigh et al. 2016; MacLachlan 2017a).

Recent changes including the increasing individualisation and decreasing socialisation of the seafaring profession may reasonably be expected to impact on the mental health of seafarers. As suggested by the ITF Seafarers' Trust (2017, p. 13), "increased support for on-board communities would increase coping mechanisms, emotional well-being, and social connectedness; as well as impacting on positive mental health outcomes". Furthermore, with seafarers of lower ranks from LMICs typically enduring the poorest terms and conditions of employment (MacLachlan 2017a), such inequities may also impact on their mental health. Accordingly, recent adverse changes and organisational justice concerns in the maritime sector indicate the need for re-evaluation by organisations and the maritime industry of working terms and conditions for seafarers.

The wider maritime industry prioritises "rationalisation" of work practices and budgets, which may lead to the infringement of rights and standards for seafarers, ultimately compromising their dignity, performance, safety, and wellbeing (McVeigh and MacLachlan 2019). As indicated above, one officer suggested that seafarers no longer wanted to be at sea due to the occupation transitioning from a 'lifestyle' to a 'job': "No-one really wants to go and do the job, but when it was a lifestyle, people wanted to go, you know. They were happy to go back to work, and I think that's gone". Maritime organisations, the industry and seafarers may benefit from a supportive and just work environment, one in which seafaring may be experienced as a rewarding profession and enjoyed again as a way of life.

Acknowledgements We are very grateful to Ms. Henriette Cox, Dr. Rudiger Stilz, Dr. Teri Lillington and Dr. Alistair Fraser for facilitating this research.

Funding Information We wish to extend our gratitude to the participants of this study, and to Shell International B.V. for financially supporting this research.

\section{Compliance with Ethical Standards}

Declaration of Interests One of the authors (JM) received a Ph.D. scholarship from Shell International B.V. to conduct this research. The other authors (MM, CC, and $\mathrm{BK}$ ) received no financial benefit for the research reported in this paper.

Publisher's Note Springer Nature remains neutral with regard to jurisdictional claims in published maps and institutional affiliations.

\section{References}

Aamodt, M.G. 2013. Industrial/organizational psychology: An applied approach. Belmont, CA: Wadsworth, Cengage Learning. 
Adams, J.S. 1965. Inequity in social exchange. In Advances in experimental social psychology, ed. L. Berkowitz, vol. 2, 267-300. New York, NY: Academic Press.

Alderton, T., M. Bloor, E. Kahveci, T. Lane, H. Sampson, M. Thomas, N. Winchester, B. Wu, and M. Zhao. 2004. The global seafarer: Living and working conditions in a globalized industry. Geneva: International Labour Office.

Allen, P., E. Wadsworth, and A. Smith. 2007. The prevention and management of seafarers' fatigue: A review. International Maritime Health 58 (1-4): 167-177.

American Psychological Association. n.d. The road to resilience: What is resilience? http://www.apa.org/helpcenter/road-resilience.aspx . Accessed 10 Dec 2018.

Andersson, G., and N. Titov. 2014. Advantages and limitations of Internet-based interventions for common mental disorders. World Psychiatry 13 (1): 4-11. https://doi.org/10.1002/wps.20083.

Bal BeșikC̣I, E., L. Tavacıoğlu, and ö Arslan. 2016. The subjective measurement of seafarers' fatigue levels and mental symptoms. Maritime Policy \& Management 43 (3): 329-343. https://doi.org/ 10.1080/03088839.2015.1047426

Bartone, P.T. 1999. Hardiness protects against war-related stress in army reserve forces. Consulting Psychology Journal: Practice and Research 51 (2): 72-82. https://doi.org/10.1037/1061-4087.51.2.72.

Bartone, P.T. 2006. Resilience under military operational stress: Can leaders influence hardiness? Military Psychology 18 (Suppl): S131-S148. https://doi.org/10.1207/s15327876mp1803s_10.

Bartone, P.T., and S.W. Hystad. 2010. Increasing mental hardiness for stress resilience in operational settings. In Enhancing human performance in security operations: International and law enforcement perspectives, ed. P.T. Bartone, B. Johnsen, J. Eid, J.M. Violanti, and J.C. Laberg, 257-272. Springfield, IL: Charles C. Thomas.

Baylon, A.M., and E.M.R. Santos. 2015. Attractions, problems, challenges, issues and coping strategies of the seafaring career: MAAP seafarers perspectives. In Safety of marine transport: Marine navigation and safety of sea transportation, ed. A. Weintrit and T. Neumann, 21-30. Leiden: CRC Press.

Bhattacharjee, S. 2017. A guide to merchant navy officer ranks. http:// www.marineinsight.com/careers-2/a-guide-to-merchant-navyofficer-ranks/. Accessed 10 Dec 2018.

BIMCO (Baltic and International Maritime Council), and International Chamber of Shipping. 2015. Manpower report: The global supply and demand for seafarers in 2015 (executive summary). http:// www.ics-shipping.org/docs/default-source/resources/safetysecurity-and-operations/manpower-report-2015-executivesummary.pdf?sfvrsn=16. Accessed 10 Dec 2018.

Bolier, L., C. Majo, F. Smit, G.J. Westerhof, M. Haverman, J.A. Walburg, H. Riper, and E. Bohlmeijer. 2014. Cost-effectiveness of online positive psychology: Randomized controlled trial. Journal of Positive Psychology 9 (5): 460-471. https://doi.org/10.1080/ 17439760.2014.910829.

Borovnik, M. 2011. Occupational health and safety of merchant seafarers from Kiribati and Tuvalu. Asia Pacific Viewpoint 52 (3): 333-346. https://doi.org/10.1111/j.1467-8373.2011.01459.x.

Careers at Sea. n.d. Choose your role. http://www.careersatsea.org/ choose-your-role/. Accessed 10 Dec 2018

Carotenuto, A., I. Molino, A.M. Fasanaro, and F. Amenta. 2012. Psychological stress in seafarers: A review. International Maritime Health 63 (4): 188-194.

Carotenuto, A., A.M. Fasanaro, I. Molino, F. Sibilio, A. Saturnino, E. Traini, and F. Amenta. 2013. The psychological general wellbeing index (PGWBI) for assessing stress of seafarers on board merchant ships. International Maritime Health 64 (4): 215-220. https://doi.org/10.5603/IMH.2013.0007.

Carr, S.C. 2005. Globalization and culture at work: Exploring their combined glocality. New York, NY: Springer.
Carter, T. 2005. Working at sea and psychosocial health problems: Report of an International Maritime Health Association Workshop. Travel Medicine and Infectious Disease 3 (2): 61-65. https://doi.org/10. 1016/j.tmaid.2004.09.005.

Carter, T. 2011. Mapping the knowledge base for maritime health: 3 illness and injury in seafarers. International Maritime Health 62 (4): 224-235.

Clare, H. 2015. Down to the sea in ships: Of ageless oceans and modern men. London: Vintage.

Collins, H. 2010. Creative research: The theory and practice of research for the creative industries. Lausanne: AVA Publishing.

Comperatore, C.A., P.K. Rivera, and L. Kingsley. 2005. Enduring the shipboard stressor complex: A systems approach. Aviation, Space and Environmental Medicine 76 (6 Suppl): B108-B118.

Corbin, J., and A. Strauss. 2015. Basics of qualitative research: Techniques and procedures for developing grounded theory. Thousand Oaks, CA: Sage.

Dimitrova, D.N., and R. Blanpain, eds. 2010. Seafarers' rights in the globalized maritime industry. Alphen aan den Rijn: Kluwer Law International.

Doyle, N., M. MacLachlan, A. Fraser, R. Stilz, K. Lismont, H. Cox, and J. McVeigh. 2016. Resilience and well-being amongst seafarers: Cross-sectional study of crew across 51 ships. International Archives of Occupational and Environmental Health 89 (2): 199209. https://doi.org/10.1007/s00420-015-1063-9.

Drozd, F., L. Mork, B. Nielsen, S. Raeder, and C.A. Bjørkli. 2014. Better days $-\mathrm{A}$ randomized controlled trial of an internet-based positive psychology intervention. Journal of Positive Psychology 9 (5): 377 388. https://doi.org/10.1080/17439760.2014.910822.

Elliott, R., and L. Timulak. 2005. Descriptive and interpretive approaches to qualitative research. In A handbook of research methods for clinical and health psychology, ed. J. Miles and P. Gilbert, 147-160. New York, NY: Oxford University Press.

Friborg, O., O. Hjemdal, J.H. Rosenvinge, M. Martinussen, P.M. Aslaksen, and M.A. Flaten. 2006. Resilience as a moderator of pain and stress. Journal of Psychosomatic Research 61 (2): 213-219. https://doi.org/10.1016/j.jpsychores.2005.12.007.

Furnham, A. 2012. Justice at work. In Humanitarian work psychology, ed. S.C. Carr, M. MacLachlan, and A. Furnham, 52-79. Basingstoke: Palgrave Macmillan.

Gill, P., K. Stewart, E. Treasure, and B. Chadwick. 2008. Methods of data collection in qualitative research: Interviews and focus groups. British Dental Journal 204 (6): 291-295. https://doi.org/10.1038/ bdj.2008.192.

Global Centre for Healthy Workplaces. 2013. London Press Release 2013: Alexandra Health, Toyal America and Royal Dutch Shell named winners in search for healthiest workplaces, 12th April 2013. https://www.globalhealthyworkplace.org/2013/04/21/ london-press-release-2013/ . Accesssed 10 Dec 2018.

Green, J., and N. Thorogood. 2005. Qualitative methods for health research. London: Sage.

Hjemdal, O., O. Friborg, T.C. Stiles, J.H. Rosenvinge, and M. Martinussen. 2006. Resilience predicting psychiatric symptoms: A prospective study of protective factors and their role in adjustment to stressful life events. Clinical Psychology \& Psychotherapy 13 (3): 194-201. https://doi.org/10.1002/cpp.488.

Hult, C., and M. Ljung. 2012. Discussion and recommendations concerning seafarers' perceptions and attitudes to work and occupation. In Swedish seafarers and seafaring occupation 2010: A study of work-related attitudes during different stages of life at sea, ed. C. Hult, 177-189. Kalmar: Kalmar Maritime Academy.

Human Rights at Sea. 2016. An introduction \& commentary to the 2011 UN Guiding Principles on Business and Human Rights \& their implementation in the maritime environment. Havant: Human Rights at Sea. https://www.humanrightsatsea.org/wp-content/ 
uploads/2015/05/HRAS-UNGP-Report-2016-low-res-sp.pdf . Accessed 10 Dec 2018.

Hystad, S.W., and H.H. Bye. 2013. Safety behaviours at sea: The role of personal values and personality hardiness. Safety Science 57: 19-26. https://doi.org/10.1016/j.ssci.2013.01.018.

Hystad, S.W., and J. Eid. 2016. Sleep and fatigue among seafarers: The role of environmental stressors, duration at sea and psychological capital. Safety and Health at Work 7 (4): 363-371.

ILO (International Labour Organization). 2006. Maritime Labour Convention, 2006, as amended. Geneva: ILO. http://ilo.org/ wcmsp5/groups/public/\%2D\%2D-ed norm/\%2D\%2D-normes/ documents/normativeinstrument/wcms_554767.pdf. Accessed 10 Dec 2018.

IMO (International Maritime Organization). 2018. Seafarer shore leave gets extra protection from 1 January 2018. London: IMO. http:// www.imo.org/en/MediaCentre/PressBriefings/Pages/01 FALConvention.aspx . Accessed 10 Dec 2018.

ITF Seafarers' Trust. 2017. Summary report from the ITF Seafarers' Trust Autumn 2016 workshop on social isolation, depression and suicide (SIDS). London: ITF Seafarers' Trust. http://www.seafarerstrust. org/programmes-2/publications/ . Accessed 10 Dec 2018.

Iversen, R.T.B. 2012. The mental health of seafarers. International Maritime Health 63(2):78-89.

Jacobs, K. 2013. Focus on 'resilience' to improve wellbeing, says Shell's Health Chief. Dinton: HR Magazine (MA Business and Leisure). $\mathrm{http}: / / w w w . h r m a g a z i n e . c o . u k / a r t i c l e-d e t a i l s /$ focus-on-resilience-toimprove-wellbeing-says-shells-health-chief . Accessed 10 Dec 2018.

Jensen, O.C., J.F.L. Sørensen, M. Thomas, M.L. Canals, N. Nikolic, and Y. Hu. 2006. Working conditions in international seafaring. Occupational Medicine 56 (6): 393-397. https://doi.org/10.1093/ occmed/kq1038.

Jepsen, J.R., Z. Zhao, and W.M.A. van Leeuwen. 2015. Seafarer fatigue: A review of risk factors, consequences for seafarers' health and safety and options for mitigation. International Maritime Health 66 (2): 106-117. https://doi.org/10.5603/imh.2015.0024.

Jeżewska, M., I. Leszczyńska, and B. Jaremin. 2006. Work-related stress at sea self estimation by maritime students and officers. International Maritime Health 57 (1-4): 66-75.

Kahveci, E. 2007. Port based welfare services for seafarers: Summary report. London: ITF Seafarers' Trust. http://www.itfseafarers.org/ files/seealsodocs/4423/WelfareReportl.pdf . Accessed 10 Dec 2018.

Kantharia, R. 2017. 12 main reasons seafarers quit sea jobs. http://www. marineinsight.com/life-at-sea/12-main-reasons-seafarers-quit-seajobs/ . Accessed 10 Dec 2018

Leppin, A.L., M.R. Gionfriddo, A. Sood, V.M. Montori, P.J. Erwin, C. Zeballos-Palacios, P.R. Bora, M.M. Dulohery, J.P. Brito, K.R. Boehmer, and J.C. Tilburt. 2014. The efficacy of resilience training programs: A systematic review protocol. Systematic Reviews 3 (20): 1-5. https://doi.org/10.1186/2046-4053-3-20.

Lipowski, M., M. Lipowska, A. Peplińska, and M. Jeżewska. 2014. Personality determinants of health behaviours of merchant navy officers. International Maritime Health 65 (3): 158-165. https:// doi.org/10.5603/imh.2014.0030.

Luthans, F. 2002. The need for and meaning of positive organizational behavior. Journal of Organizational Behavior 23 (6): 695-706. https://doi.org/10.1002/job.165.

Luthans, F., G.R. Vogelgesang, and P.B. Lester. 2006. Developing the psychological capital of resiliency. Human Resource Development Review 5 (1): 25-44. https://doi.org/10.1177/1534484305285335.

MacLachlan, M. 2016. Promoting organisational justice in medicine and health science research and practice. BMJ 352: i1048. https://doi. org/10.1136/bmj.i1048.

MacLachlan, M. 2017a. Maritime psychology: Definition, scope and conceptualization. In Maritime psychology: Research in organizational and health behavior at sea, ed. M. MacLachlan, 118. Cham: Springer.

MacLachlan, M. 2017b. Still too POSH to push for structural change? The need for a macropsychology perspective. Industrial and Organizational Psychology 10: 403-407. https://doi.org/10.1017/ iop.2017.36.

MacLachlan, M., S.C. Carr, and E. McAuliffe. 2010. The aid triangle: Recognizing the human dynamics of dominance, justice and identity. New York, NY: Zed.

MacLachlan, M., B. Kavanagh, and A. Kay. 2012. Maritime health: A review with suggestions for research. International Maritime Health 63 (1): 1-6.

MacLachlan, M., S. Cromie, P. Liston, B. Kavanagh, and A. Kay. 2013. Psychosocial and organisational aspects. In Textbook of maritime medicine (2nd ed.), ed. T. Carter. Bergen, Norway: Norwegian Centre for Maritime Medicine. http://textbook.ncmm.no . Accessed 10 Dec 2018.

Maddi, S.R. 2013. Hardiness: Turning stressful circumstances into resilient growth. New York, NY: Springer.

Maddi, S.R., and D.M. Khoshaba. 2005. Resilience at work: How to succeed no matter what life throws at you. New York, NY: Amacom.

March on Stress. 2013. March on stress news: Supporting occupational mental health in the shipping industry. http://www.marchonstress. com/index.php/news/article/73 . Accessed 10 Dec 2018.

McAuliffe, E., O. Manafa, F. Maseko, C. Bowie, and E. White. 2009. Understanding job satisfaction amongst mid-level cadres in Malawi: The contribution of organisational justice. Reproductive Health Matters 17 (33): 80-90. https://doi.org/10.1016/S0968-8080(09) 33443-6.

McVeigh, J., and M. MacLachlan. 2019. A silver wave? Filipino shipmates' experience of merchant seafaring. Marine Policy 99:283297. https://doi.org/10.1016/j.marpol.2018.10.012

McVeigh, J., M. MacLachlan, and B. Kavanagh. 2016. The positive psychology of maritime health. Journal of the Institute of Remote Health Care 7 (2): 20-28.

McVeigh, J., M. MacLachlan, R. Stilz, H. Cox, N. Doyle, A. Fraser, and M. Dyer. 2017. Positive psychology and well-being at sea. In Maritime psychology: Research in organizational and health behaviour at sea, ed. M. MacLachlan, 19-48. Cham: Springer.

Mellbye, A., and T. Carter. 2017. Seafarers' depression and suicide. International Maritime Health 68 (2): 108-114. https://doi.org/10. 5603/IMH.2017.0020.

Mission to Seafarers. 2018. Seafarers' happiness index. https://www. missiontoseafarers.org/seafarershappiness. Accessed 10 Dec 2018.

Ndjaboué, R., C. Brisson, and M. Vézina. 2012. Organisational justice and mental health: A systematic review of prospective studies. Occupational \& Environmental Medicine 69 (10): 694-700. https://doi.org/10.1136/oemed-2011-100524.

OECD (Organisation for Economic Co-operation and Development). 2017. How's life? 2017: Measuring well-being. Paris: OECD Publishing. http://www.oecd.org/statistics/how-s-life-23089679. htm . Accessed 10 Dec 2018.

Oil and Gas Job Search. 2017. Operations superintendent in London, United Kingdom. https://www.oilandgasjobsearch.com/Oil-andGas-Jobs/Operations-Superintendent-Jobs/OperationsSuperintendent/Details/1232515. Accessed 10 Dec 2018.

Oldenburg, M., and H.-J. Jensen. 2012. Merchant seafaring: A changing and hazardous occupation. Occupational \& Environmental Medicine 69 (9): 685-688. https://doi.org/10.1136/oemed-2011100619.

Oldenburg, M., H.-J. Jensen, U. Latza, and X. Baur. 2009. Seafaring stressors aboard merchant and passenger ships. International Journal of Public Health 54 (2): 96-105. https://doi.org/10.1007/ s00038-009-7067-z.

Oldenburg, M., B. Hogan, and H.J. Jensen. 2013. Systematic review of maritime field studies about stress and strain in seafaring. 
International Archives of Occupational and Environmental Health 86 (1): 1-15. https://doi.org/10.1007/s00420-012-0801-5.

Ong, A.D., C.S. Bergeman, T.L. Bisconti, and K.A. Wallace. 2006. Psychological resilience, positive emotions, and successful adaptation to stress in later life. Journal of Personality and Social Psychology 91 (4): 730-749. https://doi.org/10.1037/0022-3514. 91.4.730.

Onwuegbuzie, A.J., and N.L. Leech. 2007a. A call for qualitative power analyses. Quality \& Quantity 41 (1): 105-121. https://doi.org/10. 1007/s11135-005-1098-1.

Onwuegbuzie, A.J., and N.L. Leech. 2007b. Validity and qualitative research: An oxymoron? Quality \& Quantity 41 (2): 233-249. https:// doi.org/10.1007/s11135-006-9000-3.

Pietrzak, R.H., D.C. Johnson, M.B. Goldstein, J.C. Malley, A.J. Rivers, C.A. Morgan, and S.M. Southwick. 2010. Psychosocial buffers of traumatic stress, depressive symptoms, and psychosocial difficulties in veterans of operations enduring freedom and Iraqi freedom: The role of resilience, unit support, and postdeployment social support. Journal of Affective Disorders 120 (1-3): 188-192. https://doi.org/ 10.1016/j.jad.2009.04.015.

Plowright, D. 2011. Using mixed methods: Frameworks for an integrated methodology. London: SAGE.

Pritchard, B. 2006. Some lexical aspects of translating specialised texts. In Insights into specialized translation (volume 46 of linguistic insights: studies in language and communication), eds. M. Gotti and S. Sarcevic, 261-288. Bern: Lang.

Project MARTHA. 2016. Project MARTHA: The final report. http:// www.warsashacademy.co.uk/about/resources/martha-final-report. pdf?t=1493804055541. Accessed 10 Dec 2018.

Ravitch, S.M., and N. Mittenfelner Carl. 2016. Qualitative research: Bridging the conceptual, theoretical and methodological. Thousand Oaks, CA: SAGE.

Redzic, N.M., K. Taylor, V. Chang, M. Trockel, A. Shorter, and C.B. Taylor. 2014. An Internet-based positive psychology program: Strategies to improve effectiveness and engagement. Journal of
Positive Psychology 9 (6): 494-501. https://doi.org/10.1080/ 17439760.2014 .936966$.

Rydstedt, L.W., and M. Lundh. 2010. An ocean of stress? The relationship between psychosocial workload and mental strain among engine officers in the Swedish merchant fleet. International Maritime Health 61 (3): 168-175.

Schultz, D.P., and S.E. Schultz. 2016. Psychology and work today: An introduction to industrial and organizational psychology. 10th ed. New York, NY: Routledge.

Shoretoo. 2015. Shoretoo: Connecting you to crew. https://crewtoo.s3. amazonaws.com/wp-content/uploads/2015/09/ShoretooNewsletter-2.pdf . Accessed 10 Dec 2018.

Slišković, A. 2017. Occupational stress in seafaring. In Maritime psychology: Research in organizational and health behavior at sea, ed. M. MacLachlan, 99-126. Cham: Springer.

Spector, P.E. 2004. Social desirability bias. In The SAGE encyclopedia of social science research methods, ed. M.S. Lewis-Beck, A. Bryman, and T. Futing Liao, vol. 1, 1044-1045. Thousand Oaks, CA: SAGE.

Teo, A.R., H. Choi, and M. Valenstein. 2013. Social relationships and depression: Ten-year follow-up from a nationally representative study. PLOS ONE 8 (4): e62396. https://doi.org/10.1371/journal. pone. 0062396 .

Thomas, M. 2003. Lost at sea and lost at home: The predicament of seafaring families. Cardiff: Seafarers International Research Centre.

UNCTAD (United Nations Conference on Trade and Development). 2016. Goal 3: Good health and well-being. Geneva: UNCTAD. http://stats.unctad.org/Dgff2016/people/goal3/index.html . Accessed 10 Dec 2018

Velankar, A. 2017. Mental health and wellbeing of a seafarer. http:// www.thome.com.sg/mental-health-and-wellbeing-of-a-seafarer/ . Accessed 10 Dec 2018.

Walters, D., and N. Bailey. 2013. Lives in peril: Profit or safety in the global maritime industry? New York, NY: Palgrave Macmillan.

WHO (World Health Organization). n.d. Mental health: Suicide data. http://www.who.int/mental_health/prevention/suicide/ suicideprevent/en/ . Accessed 10 Dec 2018. 